\title{
Chosen aspects of thermographic studies on detection of physiological disorders and mechanical defects in apples
}

\author{
by P. Baranowski, W. Mazurek
}

\author{
Institute of Agrophysics, Polish Academy of Sciences, Lublin, Poland
}

\begin{abstract}
This paper presents the results of the studies on detection of fruit bruises and watercore in their tissues. Both passive and active pulse phase thermography was applied to early detect tissue defect.
\end{abstract}

\section{Introduction}

Recent years have brought new ideas of application of thermography in agrophysical studies. It is connected with new possibilities given by active thermography which enables not only to study the surface changes of object thermodynamical processes but also to have an insight into deeper layers of specimens to give information about the sizes, properties and the depth of the defects. It occurred that thermography is especially useful in agrophysical studies. Many processes of mass and energy exchange in agrophysical systems are have their reflection in the change of the surface temperature of the studied bodies. This concerns the soil-plantatmosphere system where the transport of water and gas from the soil through the plant membranes into the atmosphere and the turbulent transport of air in the atmosphere create specific actual distribution of temperature on the surface of plant and soil. Measuring this parameter considerably improves evaluation the rate of evaporation from soil and transpiration from plants. Similarly, in various stages of fruit production the dynamics of the fruit surface temperature distribution gives important information about the quality of the product. During growth, harvesting, storage and distribution fruits are the subject of constant changes of their temperature as a result of interaction with external factors such as solar radiation, frost, shading by leaves, cooling in storage houses what has an impact on their quality. An important problem in postharvest technology of fruit is nondestructive detection of defects coming from diseases, mechanical damages and physiological disorders. These defects manifest themselves with changes of thermodynamical properties of the infected tissue. In agrophysical studies of fruit quality various nondestructive testing and evaluation methods are being incorporated, including visible and near infrared imaging, spectrophotometry, colorimetry, X-ray imaging, magnetic resonance, acoustic resonance etc.. Thermography can be a promising alternative to these methods. It proved to be useful not only for the measurement of temperature changes on the surface of the investigated objects but also for detection of internal heat intrusions and heterogeneity of the thermal properties within bodies.

In this study chosen aspects of thermographic studies on detection of watercore and mechanical defects in apples are presented. The study is based on a hypothesis that internal defects and physiological disorders of fruit lead to changes of tissue thermal properties. During thermal stimulation, heterogeneities of thermal properties lead to the occurrence of thermal contrasts on the surface of these materials which can be successfully registered with the use of thermographic device.

In the process of apple sorting an important problem is how to effectively detect early bruises. In spite of the fact that bruise is the cause of rejecting the highest number of fruit in the sorting lines, the manual sorting method is still commonly used for detecting this defect. Bruise is defined as a damage of fruit tissue as a result of external forces, which cause physical changes of texture and/or chemical changes of colour, smell and taste. Two basic effects of apple bruise can be distinguished, i.e. browning and softening of fruit tissue. Existing sorting systems are not capable to effectively distinguish fruit with bruise which occur in short time before inspection. Because of some shortages of existing methods of early apple bruise a grooving interest in alternative nondestructive sorting methods is observed. Preliminary investigations with the use of thermography for detection of apple bruise indicate that this method can bring quite new possibilities under the condition that the process of heat conduction in the fruit will be precisely acknowledged and the mechanism of heat contrast creation between the bruised part and sound areas on the surface of fruit will be understood.

Watercore is a physiological internal disorder in which the intercellular air spaces around the core line become filled with fluid and a characteristic translucent tissue creates. As a result thermal properties of the affected tissues change. The disorder generally develops in more mature fruit, main contributing factors including high or low air temperatures in preharvest period, poor calcium nutrition, maturity status at harvest and cropping level. Watercore is caused by changes in membrane integrity during maturation and. Flesh tissue of apples with watercore has higher sorbitol and sucrose concentrations and lower glucose concentration than tissue without watercore. Water gathered in intercellular spaces of watercored tissue is responsible not only for the increase of a fruit mass density but also for the increase of its thermal capacity and decrease of thermal. Therefore it could be expected that fruit with watercore would be heated more slowly than fruit without watercore-affected tissue. 


\section{Material and methods \\ Material and procedure of early bruise detection in apples}

'Jonagold', 'Champion' and 'Gloster' apples (Malus domestica Borkh) were brought from the orchard directly after harvest in 2006 and then, before thermographic measurements, they were stored for 15 hours in temperature $21^{\circ} \mathrm{C}$. Special measuring system for active thermography was designed, consisting of thermographic camera VIGOcam v50, two halogen lamps (500 W each) fixed on tripod, system controlling the time of the pulse time and parameters of registration and external conditions in the thermostated laboratory (figure 1). The camera used in the experiment is sensitive in spectral range of $8-14 \mu \mathrm{m}$. The camera is constructed with the use of a $384 \mathrm{x}$ 288 microbolometric detector array. The system's thermal sensitivity (NETD is $0.08^{\circ} \mathrm{C}$ at $30^{\circ} \mathrm{C}$ of object temperature. Spatial resolution of the camera is $1 \mathrm{mrad}$. It works with a frame rate of $60 \mathrm{~Hz}$.

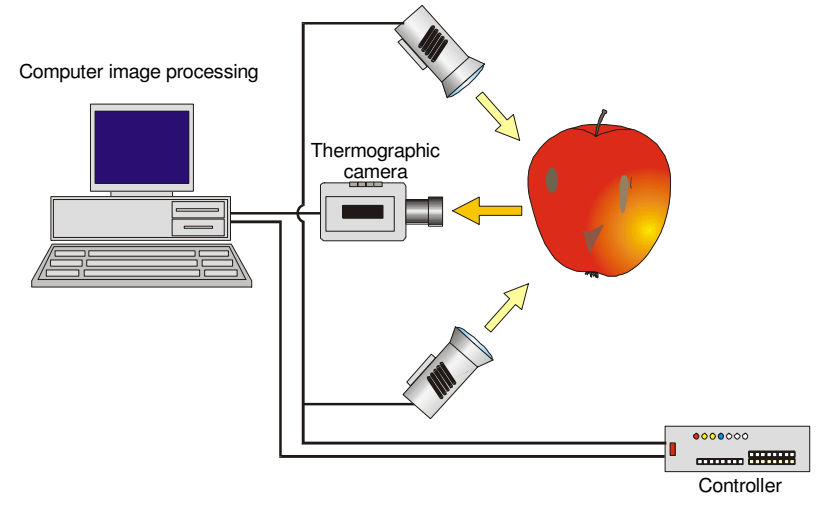

Fig. 1. A setup for early apple bruise detection

The VIGOcam v50 camera is equipped with 3.5" LCD display, video camera, laser pointer, radio link that enables remote control, SD memory card reader, microphone and loudspeaker. Connection with a PC computer is possible via USB or Ethernet port. The lens with an angular field of view of $22^{\circ}$ was used. Thermal images were registered and preliminary processed with the use of firmware software THERM v50. This software along with numerous functions for processing of thermographic data enables to export individual images and whole sequences in text format to other programs. To analyse PPT sequences in this study we used IR_View v.1.7 freesoftware created at Laval University, Computer Vision and System Laboratory.

and delivered us. The measurement of radiation temperature of apples was done in controlled external conditions. All the measurement series were performed at air temperature of $21^{\circ} \mathrm{C}$ and relative humidity of $60 \%$ in daily light. The distance between camera lens and studied apple surface was $0.5 \mathrm{~m}$. The halogen lamps were situated in a distance of $0.3 \mathrm{~m}$ from the apple surface and the distance between the centres of both lamps was $0.38 \mathrm{~m}$. The sequences of the thermograms were registered with frequency of $15 \mathrm{images} / \mathrm{second}$. Each sequence contained about 600 images. To analyse the response of the object to the heat pulse, separately images obtained during the heating process (during heat pulse duration) and images of cooling.

\section{Material and thermographic setup for watercore detection in apples}

'Gloster' apples (Malus domestica Borkh) with and without watercore were selected to provide 35 fruit in each category. The watercore occurrence in apples was stated by cutting the fruit after other measurements had been completed. After the experiment ten of the studied apples were rejected from the analysis because apart from the watercore symptoms they contained some other disorders or the volume of watercored tissue was small. The apples were transported to the laboratory directly after harvest. They were preserved in temperature of $1.5^{\circ} \mathrm{C}$ a few days before the experiment.

Thermal images of the apple surface were taken with AGEMA 880 LWB system which is sensitive in the spectral range of $8-13 \mu \mathrm{m}$. The detector in the scanner unit is mercury cadmium telluride (MCT), cooled with liquid nitrogen. The system's sensitivity (NEDT) is $0.007^{\circ} \mathrm{C}$ at $30^{\circ} \mathrm{C}$ of object temperature. It works with field frequency of $25 \mathrm{~Hz}$, line frequency of $2500 \mathrm{~Hz}$ and each frame of the image consists of 280 lines. The lens with an angular field of view of $7^{\circ}$ was used. Additionally a CCD camera registered the visible images of the studied object. The system interface and software made it possible to register and analyse simultaneously the sequences of thermal and visible range images - eight images in each sequence registered with a time interval of ten minutes. Both cameras were mounted at a height of 1.4 above the surface of fruit pointing downwards. The linear field of view of the thermal scanner at the scanned object's level was $0.14 \mathrm{~m}$. The emissivity of the fruit was set to 0.96 .

Before the measurement the fruit was moved from the cooling room $\left(1.5^{\circ} \mathrm{C}\right)$ into the thermostatted measurement site where the ambient temperature was maintained at $20^{\circ} \mathrm{C}$ and air humidity at $60 \%$. Then, the fruit was left for about 3 minutes to obtain stable conditions of measurement which was started when the fruit surface temperature increased to about $7.5^{\circ} \mathrm{C}$. 
After completing the sequences of thermal images the apple was weighed with an electronic digital balance operating at capacity up to $1000 \mathrm{~g}$ with readability of $0.001 \mathrm{~g}$. To determine the density of fruit, its volume was evaluated on the base of the visible range image analysis. The spatial scale of the image was defined using the straight-line selection tool to make a line selection that corresponds to the known distance. Then, the measurements of fruit image diameter in horizontal and vertical planes were done and the mean value of these two readings was assumed to be the diameter of the sphere representing the fruit surface. The density of the fruit was calculated as the ratio of the mass of fruit to the volume of this sphere.

\section{Results}

\section{Early bruise detection}

For the three investigated varieties the analysis of radiation temperature distribution after pulse occurrence was performed. In this study the pulsed-phase thermography (PPT) method was used. The number of images in a sequence was chosen that way that the value of fruit surface temperature during cooling approached the value close to the cold image temperature of the apple surface. Each sequence contained about 500 images registered with the frequency rate of 15 images per second. The analysis of the sequences was done with the use of IR View software.

In figure 2 an example of a cold image $(A)$ and a thermogram obtained directly after the pulse heating are presented. On the surface of the fruit two bruises were created which differed with the depth of tissue deformation. The upper bruise was shallower (up to $2 \mathrm{~mm}$ ) and the lower bruise deeper (up to $5 \mathrm{~mm}$ ).
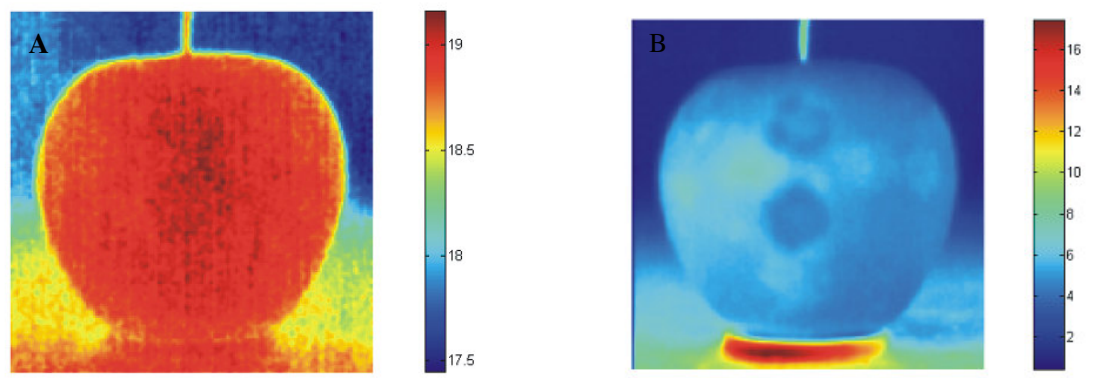

Fig. 2. Thermograms of 'Champion' apple before $(A)$ and after $(B)$ pulse heating

In figure 3 temperature courses are presented of apple surfaces above bruised and sound tissue and fitted polynomial curves of fifth range.

The curves for pixels with defect show higher decrease temperature in the first phase of cooling. Also some differences in the temperature curves were observed between the pixels above the areas differing with the depth of bruise. It suggests that PPT method can be useful to detect intensity of bruise.

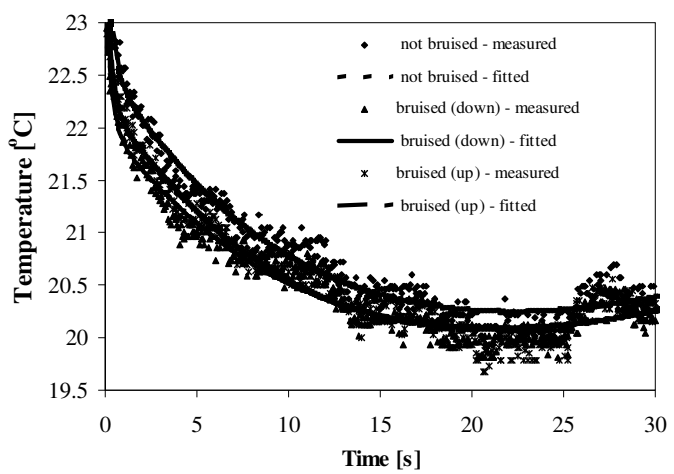

Fig. 3. Courses of radiation temperature change on the surface of sound and bruised two parts of 'Champion' apple (upper bruise reaches $2 \mathrm{~mm}$ under skin and lower bruise up to $4 \mathrm{~mm}$ )

\section{Watercore detection}

The base for analysis was the change of apple surface temperature of watercored apples and apples without watercore symptoms particular stages of warming up under temperature gradient between apple surface and surrounding air. Thermograms of an apple with watercore in particular stages of this process are presented in figure 4.

The derivative of apple temperature in time per apple mass is a good parameter to evaluate the differences in thermal properties between apples with sound and watercore affected tissues. For apples with 
watercore the rates of temperature increase per mass in particular initial stages of heating were considerably smaller than for apples with sound tissue irrespective of the part of the fruit surface considered (figure 5).

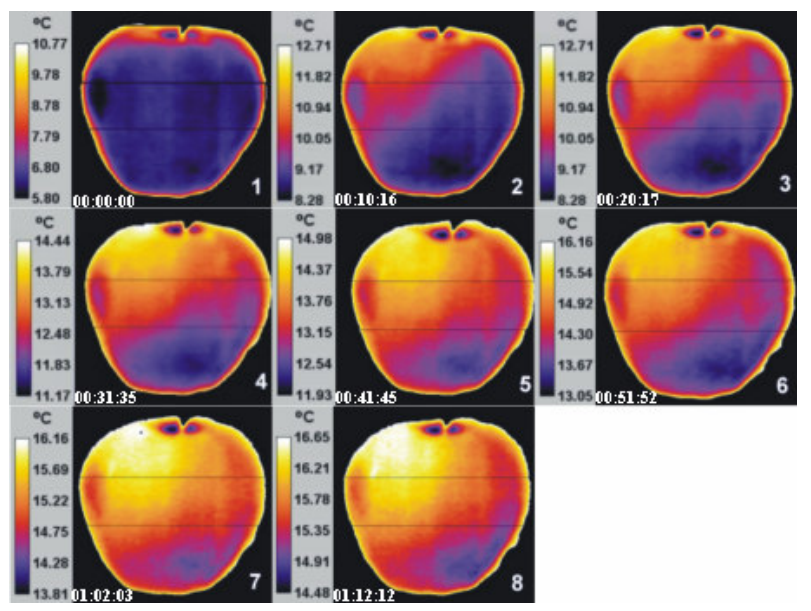

Fig. 4. Sequence of thermograms of 'Gloster' apple during heating process
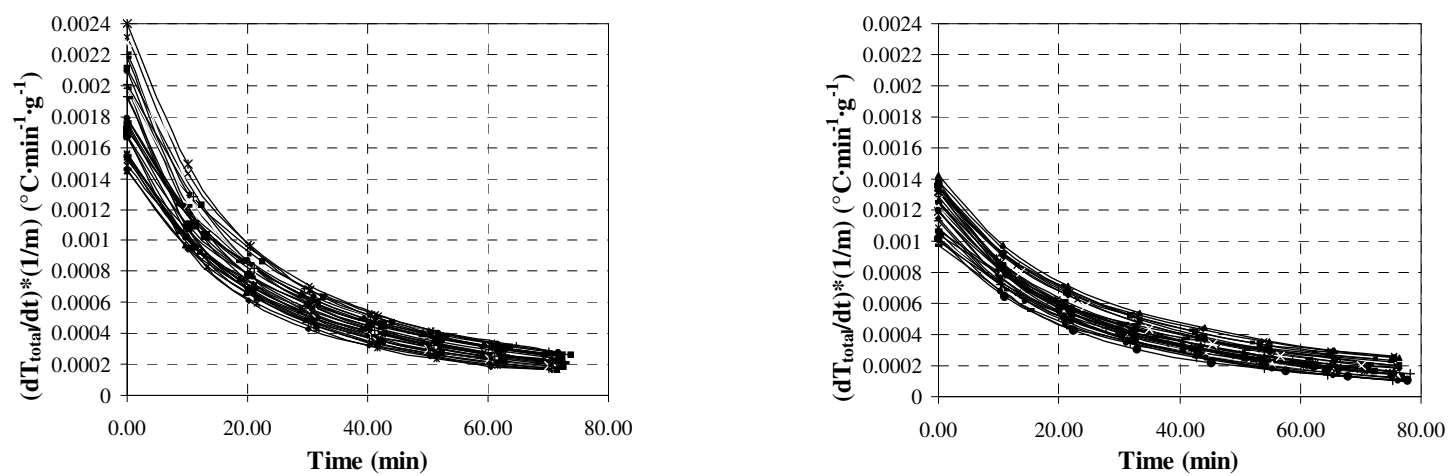

Fig. 5. Changes of heating rate in time for apples with watercore (right) and without watercore (left)

The obtained courses of temperature changes on fruit surface during the heating process showed for all the studied varieties the occurrence of temperature differences between bruised and sound parts in the range 0,5 $1,5^{\circ} \mathrm{C}$. The highest differences of radiation temperature were noticed for 'Jonagold' variety and the lowest for 'Gloster' variety, what is determined by highest differences of firmness between these two varieties.

\section{Conclusions}

Usefulness of PPT method for early apple bruises detection was stated. Characteristics of temperature decrease after pulse extinction depend on the intensity of bruise and its depth.

Thermographical measurement of the radiation temperature changes on the surface of fruit during the heating process can be used to distinguish apples with watercore disorder. The derivative of apple temperature in time per apple mass is a good parameter to evaluate the differences in thermal properties between apples with and without watercore affected tissues.

\section{Acknowledgements}

We wish to thank Dr. Clemente Ibarra-Castanedo from Laval University for valuable comments and delivering us software for PPT analysis.

\section{REFERENCES}

[1] Baranowski P., Lipecki J., Mazurek W., Walczak R.T., 2005. Detection of apple bruises with the use of thermography. Acta Agrophysica 125 vol. 6(1), in Polish.

[2] Baranowski P., Lipecki J., Mazurek W., Walczak R.T.: Detection of watercore in 'Gloster' apples using thermography. Postharvest Biol. and Technol., 47(3), (2008),358-366.

[3] Mazurek W., Baranowski P., Lipecki J.: Zastosowanie termografii w badaniach jakości owoców. VII Konferencja Krajowa Termografia i Termometria w Podczerwieni, Ustroń, 16-18.11.2006, 309-312 . 